\title{
POLÍTICAS PÚBLICAS PRESCRITAS PARA EDUCAÇÃO ESPECIAL: É POSSÍVEL PENSAR NA UNIVERSALIZAÇÃO DA ESCOLARIZAÇÃO PARA TODOS?
}

\author{
Marily Oliveira Barbosa ${ }^{1}$ \\ https://orcid.org/0000-0001-8189-4234
}

\author{
Arlindo Lins de Melo Júnior ${ }^{2}$ \\ https://orcid.org/0000-0003-2391-4772
}

RESUMO: Os alunos da Educação Especial vêm frequentando as escolas regulares e tem ascendido academicamente. Isso acontece devido as lutas dos movimentos sociais e dos próprios estudantes que buscam o comprimento dos seus direitos sociais, tais como a educação. O governo brasileiro, por intermédio das políticas públicas tem respondido as demandas por meio dos programas que prescrevem a universalização do acesso à educação. Neste sentido, perguntamos é possível pensar na universalização da escolarização para todos através das políticas públicas da Educação Especial? Objetivamos problematizar as políticas públicas voltadas ao público alvo da Educação especial, dando ênfase a entrada e permanência dos estudantes com deficiência no ambiente de escola regular em consonância com os programas de acessibilidade para a pessoa com deficiência relacionado a inclusão escolar. Esse estudo é qualitativo sob o viés da pesquisa documental. Os resultados demostram a necessidade de um melhor acompanhamento dos programas, buscando assim soluções para os problemas e novas alternativas, para que de fato as políticas saiam do prescrito e se torne realidade no cotidiano escolar.

PALAVRAS-CHAVE: Políticas Públicas. Educação. Estudantes com Deficiência.

\footnotetext{
${ }^{1}$ Doutora em Educação Especial pela Universidade Federal de São Carlos (UFSCar) - SP, Mestra em Educação pela Universidade Federal de Alagoas (UFAL) - AL, licenciada em Educação Física pela UFAL. Docente do ensino superior no Centro Universitário Maurício de Nassau (UNINASSAU) e pesquisadora do Núcleo de Estudos em Educação e Diversidade (NEEDI) da Universidade Federal de Alagoas (UFAL). Maceió-Alagoas-Brasil.marilyufal@gmail.com

${ }^{2}$ Doutorando e mestre em Educação pela Universidade Federal de São Carlos (UFSCar). Licenciado em Educação Física pela Faculdade Claretiano. Atualmente é membro do Grupo de Estudos e Pesquisas sobre Educação no Campo - (GEPEC/HISTEDBR). Faz uso do referencial teórico savianista para analisar e compreender a educação do campo (na demanda da comunidade caiçara). Universidade Federal de São Carlos, São Carlos, São Paulo, Brasil. Email: arlindolins@yahoo.com.br
} 


\section{PUBLIC POLICIES FOR SPECIAL EDUCATION: IS IT POSSIBLE TO THINK ABOUT UNIVERSALIZING SCHOOLING FOR ALL?}

ABSTRACT: Special Education students have been attending regular schools and have ascended academically. This is due to the struggles of social movements and students themselves who seek to fulfill their social rights, such as education. The Brazilian government, through public policies, has responded to the demands through programs that prescribe universal access to education. In this sense, we ask, is it possible to think about the universalization of schooling for all through the public policies of Special Education? We aim to problematize public policies aimed at the target audience of Special Education, emphasizing the entry and permanence of students with disabilities in the regular school environment in line with accessibility programs for people with disabilities related to school inclusion. This study is qualitative under the bias of documentary research. The results demonstrate the need for better monitoring of the programs, thus seeking solutions to problems and new alternatives, so that in fact policies come out of the prescribed and become a reality in the school routine.

KEYWORDS: Public Policies. Education. Students with disabilities.

\section{POLÍTICAS PÚBLICAS PARA LA EDUCACIÓN ESPECIAL: ¿ES POSIBLE PENSAR EN LA UNIVERSALIZACIÓN DE LA ESCUELA PARA TODOS?}

RESUMEN: Los estudiantes de educación especial han estado asistiendo a escuelas regulares y han ascendido académicamente. Esto se debe a las luchas de los movimientos sociales y de los propios estudiantes que buscan cumplir sus derechos sociales, como la educación. El gobierno brasileño, a través de políticas públicas, ha respondido a las demandas a través de programas que prescriben el acceso universal a la educación. En este sentido, preguntamos, ¿̇es posible pensar en la universalización de la escolarización para todos a través de las políticas públicas de Educación Especial? Nuestro objetivo es problematizar las políticas públicas dirigidas al público objetivo de Educación Especial, enfatizando la entrada y permanencia de los estudiantes con discapacidades en el entorno escolar regular en línea con los programas de accesibilidad para personas con discapacidades relacionadas con la inclusión escolar. Este estudio es cualitativo bajo el sesgo de la investigación documental. Los resultados demuestran la necesidad de un mejor monitoreo de los programas, buscando soluciones a problemas y nuevas alternativas, de modo que las políticas salgan de lo prescrito y se conviertan en una realidad en la rutina escolar.

PALABRAS-CLAVE: Políticas públicas. Educación. Estudiantes con discapacidad. 


\section{Introdução}

Na realidade educacional brasileira, é possível observar um significativo crescimento do Público alvo da Educação Especial (PAEE) o sistema regular de ensino. Em grande parte, advindo da luta dos movimentos sociais e dos próprios estudantes que buscaram o comprimento dos seus direitos por meio do prescrito nas políticas educacionais em torno da educação especial, que, em seu bojo, favorece e constitui o direito da pessoa com deficiência a ser incluído prioritariamente no modelo de ensino regular.

O direito a educação é inalienável para toda e qualquer pessoa (BRASIL, 1988; 2015), tendo imenso grau de importância na sociedade atual, visto que por intermédio dela o indivíduo tem acesso aos conhecimentos científicos e sistematizados, empoderando-se dos saberes necessários a todo e qualquer ser humano. Saviani $(2015$, p.35) coaduna com tal posicionamento ao expor que "[...] não nos é mais possível compreender a educação sem a escola", nesse sentido, a escola tem por objetivo disponibilizar aos indivíduos o acesso aos conhecimentos sistematizados, científicos, metódicos, acumulados pelas gerações anteriores.

Assim, Resultado da mobilização da nação em favor dos direitos individuais e sociais, a Constituição Federal de 1988 estabeleceu que todos são iguais perante a lei, que todos têm direito, inclusive, a uma mesma educação. No documento brasileiro denominado de "política nacional de educação especial na perspectiva da educação inclusiva" a Educação Especial aparece como:

Uma modalidade de ensino que perpassa todos os níveis, etapas e modalidades, realiza o atendimento educacional especializado, disponibiliza os serviços e recursos próprios desse atendimento e orienta os alunos e seus professores quanto a sua utilização nas turmas comuns do ensino regular (BRASIL, 2008, p. 11).

O conceito de Educação Especial e seu público alvo foi explicitado em 2013 com a Lei no 12.796 e trouxe em seu bojo a pequena parcela de estudantes que deveria ser atendido pela Educação Especial:

O poder público adotará, como alternativa preferencial, a ampliação do atendimento aos educandos com deficiência, transtornos globais do desenvolvimento e altas habilidades ou superdotação na própria rede pública regular de ensino, independentemente do apoio às instituições previstas neste artigo. (NR) (BRASIL, 2013, p. 3). 
Factualmente o conceito de Educação Especial não foi modificado na legislação brasileira, mas é preponderante ressaltar que no Brasil ela se constitui por meio da educação inclusiva na qual todas as pessoas, independente de possuir deficiência ou não deve frequentar a mesma escola regular e aprender em conjunto (BARBOSA, 2020; SCHMIDT, 2017; SCHREIBER, 2017).

A escola quando é inclusiva se efetiva enquanto espaço privilegiado para a troca de conhecimentos a partir das vivências e diferentes ações existentes dentro dela. Ao se falar de processo de escolarização, partimos do pressuposto de que a escola deve possuir ações que possam contribuir para a efetivação dos direitos de todos, relacionados a seu acesso, permanência e aprendizagem no ambiente escolar.

Cabe expor que a garantia da universalização da educação para todo cidadão brasileiro na prática parece encontrar-se distante. Apesar de evidenciamos os esforços dos movimentos sociais oriundos das universidades públicas, sindicatos, Organizações não Governamentais (ONG) e famílias a favor da educação na especificidade da educação especial. Reconhecermos que as políticas públicas da educação especial tem sido fundamentais neste processo de acesso do aluno PAEE no sistema regular de ensino, evidenciamos ao analisá-las sistematicamente a legislação que para existir uma verdadeira inclusão escolar necessitamos de outras mobilizações por parte da sociedade na fiscalização e empoderamento destas leis e principalmente nos programas previstos por elas, para assim avançamos de forma mais eficaz em uma concreta emancipação da sociedade brasileira. Schreiber (2017, p. 205-206) relata:

[...] que, as políticas de Educação Especial de 'perspectiva inclusiva', ao mesmo tempo em que disseminam um discurso em defesa da matrícula de todos os alunos no ensino regular, desqualificam o trabalho pedagógico desenvolvido na classe comum, na medida em que não disponibilizam condições adequadas para o oferecimento de um ensino de qualidade. Tal situação resulta na precarização das condições de trabalho dos professores que atuam nesse contexto e denuncia a situação de abandono para com a escolarização dos alunos da modalidade Educação Especial.

Recentemente, a Lei Brasileira de Inclusão (LBI) menciona que a Educação constitui-se como direito da pessoa com deficiência, e sua escolarização na escola regular deve ser assegurada pelo sistema educacional inclusivo em todos os níveis de aprendizado ao longo de toda a vida, de forma a alcançar o máximo desenvolvimento em relação aos seus talentos e habilidades (BRASIL, 2015) 
Desta forma, é importante recorremos aos dados do Censo Escolar (BRASIL, 2013, 2014), que arremete que houve, entre 2007 a 2014, um crescimento importante nas matriculas da educação especial. Em 2007, o número era de 410.281 matriculas; em 2014, aumentou para 701.318. O Censo Escolar revela que no decorrer dos últimos anos, houve uma mudança no quadro do PAEE. Isto se aplica pelo fato de que os/as alunos/as que outrora eram matriculados em escolas especializadas passaram a frequentar escolas regulares.

Contudo, apesar da expressividade no número de matrículas dos alunos/as com deficiência na escola regular, não se pode afirmar que estes estão efetivamente incluídos no ensino comum. Esta constatação vem embasada em estudos que demonstram que a seguridade legal, por si própria, não garante inclusão escolar. Além disso, os mesmos estudos apontam para a sensação de permanente despreparo dos docentes das salas de aula e das Salas de Recursos Multifuncionais (SRM), para a ausência de acessibilidade nas escolas e para as dificuldades técnicas no acesso aos currículos e seus conteúdos. (MENDES, 2008; CAIADO et al. 2014; ZERBATO, 2014).

Esse avanço no quantitativo de estudantes adentrando o ensino regular de ensino, representou praticamente a universalização do acesso à escola comum de alunos com ou sem deficiência, contudo, vieram à tona os problemas concernentes à qualidade da educação atestados pelas avaliações nas esferas nacionais(municipais, estaduais e federais) além das esferas internacionais que frequentemente demostram o insuficiente desempenho, assim como a dificuldade de universalização da conclusão do ensino obrigatório de qualidade (SAVIANI, 2011).

O autor citado anteriormente ainda considera que nessa discussão sobre o problema da qualidade do ensino, a formação de professores se converteu, atualmente, numa das questões mais polêmicas e de maior visibilidade, uma vez que os professores e as instituições formadoras tendem a ser apontados como vilões pelas autoridades educacionais (SAVIANI, 2011)

Por conseguinte, Prieto (2015) aponta que a relação entre igualdade e diferença na suposta universalização do acesso do PAEE ainda é complexa e deve ser pensada a partir da concepção de direitos e desigualdades. No caso do público-alvo da educação especial, por exemplo, não considerar suas especificidades equivale negligenciar um direito que já está na lei. Isso porque, ao desconsiderar a necessidade de intervenções específicas, contribui-se com a legitimação da ideia de que a matrícula na classe comum remete ao falso cumprimento do direito à educação, servindo de justificativa para não promover condições necessárias à sua aprendizagem do PAEE. 
Pensamos que alguns dos programas explicitados nas políticas públicas da educação especial apontam uma tentativa de promover condições necessárias para uma escolarização de qualidade. Alguns destes programas foram criados pelo Ministério da Educação, através da Diretoria de Políticas de Educação Especial (DPEE) e da atual Secretaria de Educação Continuada, Alfabetização, Diversidade e Inclusão (SECADI) . Tal secretaria surgiu por intermédio do Decreto no 7.690. Essa secretaria possui diversas populações como público alvo, inclusive a educação especial. Em se tratando especificamente da educação especial, a SECADI por intermédio da DPEE, fornece auxilio para diversos programas que abrangem as diversas áreas relacionas a pessoa com deficiência, dentre eles estão: o Programa Escola Acessível; Transporte Escolar Acessível; Salas de Recursos Multifuncionais; Formação Continuada de Professores na Educação Especial; BPC na Escola; Acessibilidade à Educação Superior; Educação Inclusiva: direito à diversidade; Livro Acessível; Prolibras; Centro de Formação e Recursos: CAP - Centro de Apoio para Atendimento às Pessoas com Deficiência Visual; CAS - Centros de Capacitação de Profissionais da Educação e de Atendimento às Pessoas com Surdez;e, NAAHS - Núcleos de Atividades de Altas Habilidades/Superdotação.

Cabe mencionar que neste estudo objetivamos problematizar as políticas públicas voltadas ao público alvo da Educação especial, dando ênfase a entrada e permanência dos estudantes com deficiência no ambiente de escola regular em consonância com os programas de acessibilidade para a pessoa com deficiência e com os expostos na Lei brasileira de inclusão relacionado a educação e a inclusão escolar.

\section{Aspectos metodológicos}

Esse estudo de natureza qualitativa sob o viés da pesquisa documental. É desenvolvida com base em material já elaborado e utiliza-se de documentos como fonte de dados. Os documentos postos para esse tipo de pesquisa são caracterizados como arquivos escritos, que tem por objetivo o esclarecimento de algum conteúdo que contribua de alguma forma para a investigação de determinado fato ou fenômeno (GIL, 2011). Os documentos variam segundo suas fontes, podendo estes ser de arquivos públicos ou particulares, esses se constituem fontes fidedignas de dados e oferecem conhecimentos objetivos da realidade (MARCONI: LAKATOS, 2012).

Ademais, a análise de dados foi realizada qualitativamente por meio de categorias disponibilizadas no decorrer do texto, após leitura dos documen- 
tos que regem as políticas públicas relacionados a área da educação especial, tendo por foco as questões em nível educacional, buscando observar os pontos relacionados com os objetivos do estudo.

\section{Resultado e análise de dados}

\section{Analisando a Lei Brasileira de Inclusão (Estatuto da Pessoa com Deficiência)}

A Lei Brasileira de Inclusão da Pessoa com Deficiência № 13.146, de 6 de julho de 2015 expõe inúmeros aspectos relacionadas ao PAEE. Inicialmente a referida Lei explicita quem são os sujeitos público alvo dela, conceitua alguns termos relacionados ao corpo da legislação e expõe questões relacionadas aos diversos direitos das pessoas com deficiência. A lei é extensa e possui 127 artigos que abarcam inúmeros aspectos que se relacionam diretamente a pessoa com deficiência. Nesse estudo em questão serão observados os aspectos educacionais e mais especificamente dos programas educacionais de acessibilidade disponibilizados pelo governo federal para alcançar a universalização do direito do PAEE a adentrar o sistema regular de ensino. No quadragésimo primeiro artigo da LBI constatamos a incumbência do poder público no aprimoramento dos sistemas educacionais, tendo em vista a garantia das "condições de acesso, permanência, participação e aprendizagem, por meio da oferta de serviços e de recursos de acessibilidade que eliminem as barreiras e promovam a inclusão plena" (BRASIL, 2015, p. 9). Anteriormente se configurava incluso o estudante que tivesse acesso, permanência e aprendizagem. No dispositivo da LBI é acrescentado a participação como condição indispensável ao estudante.

Ainda, ao analisarmos a LBI compreendemos a importância dos programas de acessibilidade para o PAEE. Dentre esses podemos citar: "disponibilização de programas de capacitação dos profissionais de educação, tanto em serviço como durante a formação" (BRASIL, 2015, p. 10). Fica então evidenciado a preocupação das políticas públicas da educação especial para além da escolarização dos alunos PAEE, focando também na formação dos professores da sala regular e SRM.

É possível observar ainda o fato dos programas educacionais de acessibilidade serem citados na LBI (BRASIL, 2015) remete a importância dos programas educacionais de acessibilidade para uma educação de qualidade. Sendo preponderante mencionar que a LBI discorre da importância destes programas de acessibilidade para que o indivíduo com deficiência alcance um lugar na sociedade e também no mercado de trabalho. 


\section{Programas de acessibilidade voltados à pessoa com deficiência}

Dentro do conjunto de programas voltado a inclusão escolar, todos, em sua unanimidade mencionam a necessidade de ações voltada à acessibilidade, e alguns destes programas tem o foco direto nesta questão, é o caso do Programa Escola Acessível; Transporte Escolar Acessível; Acessibilidade à Educação Superior; e, o programa livro acessível, que embora não fale sobre a acessibilidade física, fala sobre o acesso aos conteúdos e a acessibilidade das informações. Antes de falar sobre os programas convém aqui ressaltar que acessibilidade é constituída por um espaço acessível, que permite ao indivíduo ir e vir, participar de todas as atividades que o local proporcione, sempre com autonomia, segurança e conforto, independente das habilidades e restrições que o indivíduo possua (DISCHINGER; BINS ELY, 2005). A LBI define ainda que:

[...] barreiras é qualquer entrave, obstáculo, atitude ou comportamento que limite ou impeça a participação social da pessoa, bem como o gozo, a fruição e o exercício de seus direitos à acessibilidade, à liberdade de movimento e de expressão, à comunicação, ao acesso à informação, à compreensão, à circulação com segurança, entre outros (BRASIL, 2015, p.11)

Por isso a necessidade de assegurar que as instituições públicas e privadas, inclusive a escola regular ofereça ambientes acessíveis a toda a população. O programa escola acessível, surgiu para auxiliar na promoção das condições de acessibilidade ao ambiente físico, aos recursos didáticos e pedagógicos, à comunicação e informação nas escolas públicas de ensino regular. Desta feita, o Ministério da Educação criou o Programa Escola Acessível:

[...] considerando a necessidade de adotar medidas de apoio, no âmbito do sistema regular de ensino, para garantir as condições de acessibilidade ao meio físico, aos recursos didáticos e pedagógicos e às comunicações e informações, com vistas à efetivação do direito à educação das pessoas com deficiência. (BRASIL, 2011b, p.2).

O Programa Escola Acessível constitui uma das principais medidas para a consolidação de um sistema educacional inclusivo, auxiliando para a efetivação da inclusão plena, condição indispensável para uma educação de qualidade. 0 programa prevê para as escolas auxílios diversos voltados a acessibilidade. Está incluso financiamento, orientação sobre a execução dos recursos financeiros nas escolas para a instalação do programa, bem como apoio para a criação e implementação do plano de atendimento, uma vez que a escola deverá: 
Adequar arquitetônica ou estruturalmente, os espaços físicos reservados à instalação e funcionamento de salas de recursos multifuncionais, a fim de atender os requisitos de acessibilidade; adequar sanitários, alargar portas e vias de acesso, construir rampas, instalar corrimão e colocar sinalização tátil e visual; Adquirir mobiliário acessível, cadeira de rodas, material desportivo acessível e outros recursos de tecnologia assistiva (BRASIL, 2011a, p. 14).

Tais ações encontram-se expostos na resolução no 27 , sob a forma de como utilizar o recurso financeiro obtido pelo programa, uma vez que este é destinado à aquisição dos materiais citados acima. Além dos materiais, a resolução prevê a contratação de serviços para construção e adequação dos bens materiais necessários a acessibilidade da pessoa com deficiência (BRASIL, 2012a).

Juntamente com este programa, criou-se o Programa transporte escolar acessível. Observou-se que dentre os principais motivos para o não acesso das pessoas com deficiência à escola foi à falta de transporte acessível, registrando os seguintes percentuais regionais: "Nordeste -35\%; Centro Oeste -33\%; Norte - 32\%; Sudeste - 28\%; Sul - 23\%". A região nordeste foi a que teve maior índice, ganhando inclusive da região norte. Para atendimento a essa demanda, o MEC, por meio de ação conjunta entre a SECADI e o Fundo Nacional de Desenvolvimento da Educação - (FNDE) busca viabilizar aquisições e distribuição de veículos para o transporte escolar acessível (BRASIL, 2011a).

Tais ações são necessárias, pois como afirma Silva (2006), a escola deverá se preparar para acolher todos os alunos, inclusive os alunos com deficiência, e para isso deve realizar uma ação conjunta em que seja promovido o transporte escolar acessível, a acessibilidade física, adaptação de mobiliário e inclusive produção de materiais didáticos pedagógicos acessíveis, visando assim a obtenção do sucesso escolar de toda a diversidade de alunos que frequentam o ambiente escolar.

Existe a necessidade de um maior empenho sobre a acessibilidade de informação e comunicação, voltada as pessoas com deficiência visual e auditiva, buscando assegurar este tipo de acessibilidade, o governo criou o programa livro acessível, que tem por objetivo:

Promover a acessibilidade no âmbito do Programa Nacional Livro Didático - PNLD e Programa Nacional da Biblioteca Escolar - PNBE, assegurando aos estudantes com deficiência visual matriculados em escolas públicas da educação básica, livros em 
formatos acessíveis. O programa é implementado por meio de parceria entre SECADI, FNDE, IBC e Secretarias de Educação, às quais se vinculam os CAP - Centro de Apoio Pedagógico a Pessoas com Deficiência Visual e os NAPPB - Núcleo Pedagógico de Produção Braille (BRASIL, 2010, p.2).

Por meio desse programa, os alunos com deficiência visual que se utilizam do sistema Braille e áudio visual poderão usufruir com qualidade dos livros didáticos disponibilizados nas escolas do ensino regular de ensino. As ações do programa livro acessível são:

Desenvolvimento do Sistema de Informação Digital Acessível - Mecdaisy, que possibilita acessar o texto por meio de áudio, caráter ampliado e diversas funcionalidades de navegação pela estrutura do livro; Realização de seminários de formação dos profissionais envolvidos na produção de material didático acessível em formato digital e em braille; Disponibilização de laptop para estudantes cegos dos anos finais do ensino fundamental, do ensino médio, da EJA e educação profissional; Criação do Acervo Digital Acessível - ADA, ambiente virtual destinado a postagem de materiais digitais e a produção coletiva de livros em Mecdaisy (BRASIL, 2011, p.1).

Cabe aqui ressaltar que tais ações estão interligadas a política nacional do livro, criada através da Lei no 10.753, em seu Art. 1ํㅡ, esta Lei institui a Política Nacional do Livro, mediante as seguintes diretrizes:

I - assegurar ao cidadão o pleno exercício do direito de acesso e uso do livro; II - o livro é o meio principal e insubstituível da difusão da cultura e transmissão do conhecimento, do fomento à pesquisa social e científica, da conservação do patrimônio nacional, da transformação e aperfeiçoamento social e da melhoria da qualidade de vida;[...] XII - assegurar às pessoas com deficiência visual o acesso à leitura (BRASIL, 2003, p. 1).

Indo ao encontro do exposto acima, observamos que o Brasil tem desenvolvido diversas formas de assegurar o acesso ao conhecimento, principalmente por intermédio dos dispositivos legais.

O Decreto 6571/2008 em seu Artigo 3o, parágrafo 2으, determina que o Ministério da Educação prestará apoio técnico e financeiro à:

Produção e distribuição de recursos educacionais para a acessibilidade que incluem livros didáticos e para didáticos em 
braile, áudio e Língua Brasileira de Sinais - LIBRAS, laptops com sintetizador de voz, softwares para comunicação alternativa e outras ajudas técnicas que possibilitam o acesso ao currículo (BRASIL, 2008, p.17).

Ainda sobre o livro acessível, o decreto 7084/2010 que em seu Artigo 280 determina que "o Ministério da Educação adotará mecanismos para promoção da acessibilidade nos programas de material didático destinados aos alunos da educação especial e seus professores das escolas de educação básica públicas", e, em seu parágrafo único que: "os editais dos programas de material didático poderão prever obrigações para os participantes relativas à apresentação de formatos acessíveis para atendimento do público da educação especial" (BRASIL, 2010, p.1).

Para transformar os livros didáticos tradicionais em formato tecnológico e acessível, o governo teve de recorrer a novas estratégias e para isso se utilizou do Mecdaisy. A nota técnica 21/2012 relata que o Mecdaisy, é "uma solução tecnológica que permite a produção de livros em formato digital acessível, no padrão Daisy". Este foi:

\begin{abstract}
Desenvolvido por meio de parceria com a Universidade Federal do Rio de Janeiro, o Mecdaisy possibilita a geração de livros digitais falados e sua reprodução em áudio, gravado ou sintetizado. Este padrão apresenta facilidade de navegação pelo texto permitindo a reprodução sincronizada de trechos selecionados, o recuo e o avanço de parágrafos e a busca de seções ou capítulos. Possibilita também, anexar anotações aos arquivos do livro, exportar o texto para impressão em Braille, bem como a leitura em caracteres ampliados (BRASIL, 2012, p.1).
\end{abstract}

Desta feita, é possível observar que o Brasil tem avançado nas questões relacionadas a acessibilidade de informação para a população da educação especial. Cada cidade conta com um centro de apoio que auxilia na questão do livro didático acessível e também possibilita que cada professor encaminhe seu material e transforme para o formato acessível. E tais ações são relacionadas a todos os níveis da educação, desde o ensino fundamental até o superior.

Em se tratando da acessibilidade no ensino superior, o governo criou o Programa Incluir, uma vez que o Decreto no 7.234/ 2010 dispõe através do Programa Nacional de Assistência Estudantil (PNAES), em seu artigo 3ำ que: "O PNAES deverá ser implementado de forma articulada com as atividades de ensino, pesquisa e extensão, visando o atendimento de estudantes regularmente 
matriculados em cursos de graduação presencial das instituições federais de ensino superior". O mesmo decreto menciona as diversas áreas de atendimento, inclusive os relacionados a população da educação especial, ao mencionar a assistência estudantil voltado ao "acesso, participação e aprendizagem de estudantes com deficiência, transtornos globais do desenvolvimento e altas habilidades e superdotação" (BRASIL, 2010b, p.1).

O programa incluir mencionado anteriormente tem como objetivo "promover a inclusão de estudantes com deficiência, na educação superior, garantindo condições de acessibilidade nas Instituições Federais de Educação Superior". E suas ações são diretamente relacionadas a:

Adequação arquitetônica para acessibilidade nos diversos ambientes das IFES rampa, barra de apoio, corrimão, piso e sinalização tátil, sinalizadores, alargamento de portas e vias, instalação de elevadores, dentre outras; Aquisição de recursos de tecnologia assistiva para promoção de acessibilidade pedagógica, nas comunicações e informações, aos estudantes com deficiência e demais membros da comunidade universitária computador com interface de acessibilidade, impressora Braille, linha Braille, lupa eletrônica, teclado com colmeia, acionadores acessíveis, dentre outros; Aquisição e desenvolvimento de material didático e pedagógico acessíveis; Aquisição e adequação de mobiliários para acessibilidade (BRASIL, 2010b, p.1)

Desta feita, as ações visam auxiliar na acessibilidade física, de informação e comunicação, auxiliando assim na inclusão do aluno com deficiência dentro do nível superior, pois para se efetivar a inclusão, é necessária que a instituição educacional possua uma boa acessibilidade conectada a sociedade em geral. Quando os espaços não estão adequados às necessidades de todos, uma parte dela fica privada de autonomia e independência, complicando a sua efetiva inclusão.

Vizioli e Peres (2004) explicam que a acessibilidade é a possibilidade e a condição de alcance para utilização das edificações, espaço mobiliário e equipamentos urbanos. Oliveira (2003) relata que, apesar de sua relevância para a vida do cidadão e mesmo existindo diversos dispositivos legais que a garanta, infelizmente este importante elemento para a vida em comunidade ainda não é uma realidade em muitos espaços da sociedade brasileira. Talvez por isso que Silva (2006) considere que o fato de serem poucas as pessoas com deficiência que encontramos nos diferentes espaços sociais deve-se as barreiras arquitetônicas, ausência de sinalizações, transporte inadequado, entre outros. 
Dito isto, cabe a sociedade em geral criar mecanismos para o cumprimento dos dispositivos legais, uma vez que o Brasil possui diversas leis que asseguram os direitos da pessoa com deficiência, inclusive os relacionados a acessibilidade. São diversas as políticas públicas, no entanto ainda há muito a ser feito, tanto por parte do cumprimento das leis, como também pelo cumprimento dos programas de acessibilidade dentro do ambiente escolar, pois muitos deles têm auxílio financeiro, conhecimento sobre a lei, contudo pouco ou quase nada é feito para mudar a realidade da inclusão da pessoa com deficiência no ambiente escolar.

\section{Considerações finais}

Evidenciamos que as políticas públicas nacionais voltadas a educação se consolidam por intermédio dos programas do governo, se tratando da pessoa com deficiência são diversos os programas que visam o acesso e permanência do PAEE no sistema educacional, contudo existe um longo caminho a ser seguido para se alcançar a uma educação de qualidade para os estudantes com deficiência.

A entrada e permanência dos alunos PAEE versus qualidade de ensino nos arremete que muitas outras pesquisas pertinentes a isso deveram ser forjadas a luz da ciência, pois, constatamos que os programas de acessibilidade para a pessoa com deficiência e o programa "Salas de Recursos Multifuncionais" entre outros, são relevantes para trilhar um caminho de uma educação de excelência ainda que utópica no contexto nacional e internacional.

Como exposto acima, os programas direcionados a população da educação especial são diversos e dizem respeito as peculiaridades de cada deficiência. As políticas públicas educacionais no que tange os decretos, lei e outros dispositivos legais conseguem por meio do prescrito incluir e auxiliar na solução para uma inclusão escolar do PAEE no ambiente de ensino regular ainda que sejam necessários olhares para contemplar as especificidades da educação especial no que diz respeito a cada deficiência.

Há necessidades de embates educacionais para além da Educação Especial. E que esses envolvem toda a sociedade brasileira. Mesmo com a imposição dos diversos dispositivos legais discutidos nesse artigo quanto ao direito de escolarização, ainda há dificuldade no cumprimento de tais demandas, visto que elas precisam de ações que vão além do prescrito. É necessário pensar na formação de professores, na qualidade estrutural da escola e no reconhecimento dos docentes. Educação Especial numa visão de educação 
inclusiva pressupõe o envolvimento de todo a comunidade escolar.

Entendemos que no momento em que é lançada a política pública educacional ela surge como uma solução para os problemas, no entanto quando chega as escolas encontram-se diversos obstáculos para pôr em prática o que é exposto na teoria. Os professores se sentem despreparados para atuar com os alunos, a escola por sua vez tem dificuldade em transformar o ambiente numa estrutura acessível, quer seja pela instalação elétrica inadequada ou pela falta de técnicos qualificados para instalar as estruturas e equipamentos eletrônicos.

Por conseguinte, urge a necessidade de um melhor acompanhamento dos programas, buscando assim soluções para os problemas e novas alternativas, para que de fato as políticas saiam dos papéis e se tornem prática no cotidiano escolar. Todos os programas visam incluir o aluno, e para que isso aconteça existe a necessidade da teoria virar ação em todos os ambientes educacionais. De certo há muito a avançar, mas é a permanência nas reivindicações que auxiliara a mudança desta realidade.

\section{Referências}

ANDRADE, M.S.A.; et al. Pessoas com deficiência rumo ao processo de inclusão na educação superior. Revista Index. Barreiras, BA, v. 10, n12 p. 01 - 05, 2007

BARBOSA, M. O. Escolarização de estudantes surdos e os profissionais envolvidos: o foco nos dispositivos legais brasileiros. Revista Exitus, v. 10, p. 020008-29, 2020.

BRASIL. Constituição da República Federativa do Brasil. Brasília: Imprensa Oficial, 1988.

BRASIL. Lei de Diretrizes e Bases da Educação Nacional, LDB 9.394, de 20 de dezembro de 1996. Ministério da Educação. 1996.

BRASIL. Lei no 10.753, de 30 de outubro de 2003: Institui a política nacional do livro. Ministério da Educação. 2003.

BRASIL. Decreto no 5.296, de 02 de dezembro de 2004. Estabelece normas gerais e critérios básicos para a promoção da acessibilidade das pessoas portadoras de deficiência ou com mobilidade reduzida, e dá outras providências. 2004.

BRASIL. Portaria normativa no- 13, de 24 de abril de 2007. Dispõe sobre a 
criação do "Programa de Implantação de Salas de Recursos Multifuncionais". 2007

BRASIL. Política Nacional de Educação Especial na Perspectiva da educação Inclusiva. Brasília, MEC/SEESP, 2008.

BRASIL a. Decreto $n^{\circ}$ 6.949, 25 de agosto de 2009. Disponível em: <http:// www.planalto.gov.br/ccivil_03/_ato2007-2010/2009/decreto/d6949.htm>. Acesso em 30 de maio de $20 \overline{1} 0$.

BRASIL b. Resolução no 4, de 2 de outubro de 2009. Institui Diretrizes Operacionais para o Atendimento Educacional Especializado na Educação Básica, modalidade Educação Especial. 2009.

BRASIL a. Decreto 7084 de 27 de janeiro de 2010.Dispõe sobre os programas de material didático e dá outras providências.2010.

BRASIL b. Decreto no 7.234 de 19 de julho de 2010. Dispõe sobre o Programa Nacional de Assistência Estudantil - PNAES. 2010

BRASIL a. Manual do Programa Escola Acessível. Ministério da Educação. Secretaria de Educação Continuada, Alfabetização, Diversidade e Inclusão. Brasília, Distrito Federal.2011

BRASIL b. Nota técnica no 42/ 2011 / MEC / SECADI / DPEE. Ministério da Educação. Secretaria de Educação Continuada, Alfabetização, Diversidade e Inclusão. Brasília, Distrito Federal, Brasil, 2011.

BRASIL c. Decreto no 7.611, de 17 de novembro de 2011. Dispõe sobre a educação especial, o atendimento educacional especializado e dá outras providências. Brasília, Distrito Federal, Brasil, 2011.

BRASIL d. Nota técnica no 005/ 2011 / MEC / SEESP / GAB. Publicação em formato digital acessível - Mecdaisy. Brasília, Distrito Federal, Brasil, 2011.

BRASIL a. Resolução no 27 de 27 de julho de 2012. Ministério da Educação. Fundo Nacional de Desenvolvimento da Educação. Conselho Deliberativo. 2012

BRASIL. b. Decreto no 7.690, de 2 de março de 2012. Aprova a Estrutura Regimental e o Quadro Demonstrativo dos Cargos em Comissão e das Funções Gratificadas do Ministério da Educação. 2012.

BRASIL. Lei no 12.796, de 4 de abril de 2013. Altera a Lei no 9.394, de 20 de dezembro de 1996, que estabelece as diretrizes e bases da educação nacio- 
nal, para dispor sobre a formação dos profissionais da educação e dar outras providências. 2013.

BRASIL. MEC. Dados Finais. Anexo II - Censo Escolar. Brasília: MEC/CNE, 2014b.

BRASIL. Lei no 13.146, de 6 de julho de 2015. Institui a Lei Brasileira de inclusão da Pessoa com Deficiência (Estatuto da Pessoa com Deficiência), Brasileira, 2015.

BRASIL. Decreto no 9.465 de 2 de janeiro de 2019. Aprova a Estrutura Regimental e o quadro demonstrativo dos cargos em comissão e das funções de confiança do Ministério da Educação, remaneja cargos em comissão e funções de confiança e transforma cargos em comissão do Grupo-Direção e Assessoramento Superiores -DAS e Funções Comissionadas do Poder Executivo -FCPE. Presidência da República, Brasília, 2019.

CAIADO, K. R. M; GONCALVES, T. G. G. L.; TELLES, R. T. G.; MACALLI, A C. Deficiência e desigualdade social: O recente caminho para a escola. Rev. Cad. CEDES. v. 34, n.93, p. 241-260. Maio/agos. 2014.

DISCHINGER, M.; BINS ELY, V.H. M. Promovendo acessibilidade nos edifícios públicos: Guia de avaliação e implementação de normas técnicas. Santa Catarina: Ministério Público do Estado, 2005.

GIL, A. C. Métodos e técnicas de pesquisa social. 6 ed. 4 reimpr. São Paulo: Atlas, 2011.

MARCONI, M. A.; LAKATOS, E. M. Técnicas de pesquisa: planejamento e execução de pesquisas, amostragens e técnicas de pesquisa, elaboração, análise e interpretação de dados. 7 ed. 6 reimpr. São Paulo: atlas, 2012.

MENDES, E.G Pesquisa sobre inclusão escolar: Revisão da agenda de um grupo de pesquisa. Revista Eletrônica de Educação, v. 2, n. 1, p 1-25, jun. 2008. Disponível em: <http://www.reveduc.ufscar.br/index.php/reveduc/article/ viewFile/11/11 >. Acesso em: 24 de nov de 2014.

OLIVEIRA, E. T. G. Acessibilidade na Universidade Estadual de Londrina: o ponto de vista do estudante com deficiência, 2003. 168 f. Dissertação (mestrado) - Universidade Estadual Paulista, Faculdade de Filosofia e Ciências, 2003.

PRIETO, R.G. Entrevista cedida a revista olhares. Rev. Olh@res, Guarulhos, v. 3, n. 1, p. 219-236. Maio, 2015.

SAVIANI, D. Formação de professores no Brasil: dilemas e perspectivas. Poiesis Pedagogica, v. 9, n.1 p. 07-19, jan/jun.2011. 
SAVIANI, D. O conceito dialético de mediação na pedagogia histórico-crítica em intermediação com a psicologia histórico-cultural. Germinal: Marxismo e Educação em Debate, Salvador, v. 7, n. 1, p. 26-43, jun. 2015.

SCHMIDT, C. Transtorno do espectro autista: onde estamos e para onde vamos. Psicologia em Estudo, Maringá, v. 22, n. 2, p. 221-230, abr./jun. 2017.

SCHREIBER, D. V. A. F. A organização do trabalho docente na classe comum com os alunos da modalidade educação especial: controvérsias da desqualificação do trabalho pedagógico. In: GARCIA, R. M. C. (org.) Políticas de educação especial no Brasil no início do século XXI. Florianópolis, SC, 2017. p.161210.

SILVA, L. M. O estranhamento causado pela deficiência: preconceito e experiência. Revista Brasileira de Educação, vol. 11, n. 33, set./dez. 2006.

VIZIOLI, S. H. T.; PERES, P. T. O direito de ir e vir - Acessibilidade dos espaços de circulação do centro de São Paulo. Revista Eletrônica de Ética e Cidadania São Paulo, v.1. n 1, p. 186 -196, agosto, 2004.

ZERBATO, A.P. O papel do professor de Educação Especial na proposta do coensino. 2014. Dissertação (Mestrado em Educação Especial) - Programa de Pós-graduação em Educação Especial, Universidade Federal de São Carlos, São Paulo, 2014. 